\title{
Interactive Acquisition and Sharing: Understanding the Dynamics of HIVIAIDS Information Networks
}

\author{
Tiffany C. Veinot \\ School of Information, University of Michigan, 1085 South University Avenue, 303B West Hall, \\ Ann Arbor, Ml 48109-1107. E-mail: tveinot@umich.edu
}

HIVIAIDS information is an important resource for people affected by the disease, particularly information that they obtain from other people. Although existing studies reveal that people with HIVIAIDS (PHAs) rely extensively on personal relationships for HIVIAIDS information, they explain little about how this happens as a social process. To investigate how PHAs and their friends/family members acquire and share network-mediated HIVIAIDS information, semistructured, in-depth interviews were conducted in three rural regions of Canada. Interviews were carried out with 114 PHAs, their friends/family members, and health care and service providers. A network solicitation and chain-referral recruitment procedure was used to delineate HIVIAIDS information networks for participants. Interview data were analyzed qualitatively and compared to Haythornthwaite's (1996) concepts of network-mediated information processes and Talja and Hansen's (2006) collaborative information behavior framework. Findings revealed that participants obtained HIVIAIDS information from their networks through five interactive processes: joint seeking, tag-team seeking, exposure, opportunity, and legitimation. The results of this study advance information behavior theory by pointing to the interactive character of information behavior and introducing new concepts to describe everyday life collaborative information behavior. This research also demonstrates the extensive interplay between health information exchange and the sharing of emotional support. The insights emanating from this study suggest that health information practice might benefit from a focus on program strategies such as building information network capacity, developing collaborative information retrieval systems and relationship-building, in addition to the more traditional library-related concerns of reference encounters, collections, and institutional Web sites.

Received December 30, 2008; revised May 13, 2009; accepted May 13, 2009

(C) 2009 ASIS\&T • Published online 6 July 2009 in Wiley InterScience (www.interscience.wiley.com). DOI: 10.1002/asi.21151

\section{Introduction}

Although existing studies reveal that people with HIV/AIDS (PHAs) ${ }^{1}$ rely on personal relationships for HIV/AIDS information, they explain little about how this happens as a social process. This gap in understanding is symptomatic of a general lack of research regarding the relational dynamics of information networks, despite information behavior researchers' long-standing interest in mapping social networks as channels for obtaining information (see, for example, Crane, 1972; Cronin, 1982; Haythornthwaite, 1996; Hersberger, 2003). Additionally, despite the growing research interest regarding collaborative information seeking and sharing within workplaces and academic settings (e.g., Hansen \& Järvelin, 2005; Prekop, 2002; Reddy \& Jansen, 2008; Sonnenwald \& Pierce, 2000; Talja, 2002), little is known about the extent to which these behaviors may be undertaken in everyday life contexts (Talja \& Hansen, 2006).

As an everyday life experience, dealing with HIV/AIDS provides a rich context for examining information exchange through social networks since HIV/AIDS information is an important resource for many PHAs and their friends/family members (Brashers, 2001; Brashers, Neidig, Haas, Dobbs, Cardillo, \& Russell, 2000; Health Canada, 2000; Huber \& Cruz, 2000), and interpersonal sources of HIV/AIDS information are very important for people affected by HIV/AIDS (Health Canada, 2000; Hogan \& Palmer, 2005; Huber \& Cruz, 2000). Accordingly, this research draws from this information-intense situation in order to examine broader concepts regarding everyday life information exchange.

In this research, I investigate the question of how PHAs and their friends/family members acquire and share information within their social networks. As I consider this question, I draw upon concepts of network-based information

\footnotetext{
${ }^{1}$ People with HIV/AIDS in Canada commonly use the term "PHA" as a term to represent their personal identities. This term arose out of the Canadian HIV/AIDS movement as an assertion of a belief in the empowerment and survival of people with the disease. Out of respect for this collective selfidentification, the term "PHA" is used throughout this research.
} 
processes posited by Haythornthwaite (1996) and contained in Talja and Hansen's (2006) model of collaborative information behavior. Semi-structured, in-depth interviews were conducted in three rural regions of Canada. Interviews were carried out with PHAs and their friends/family members. Additionally, key informant interviews (Gilchrist \& Williams, 1999) were conducted with health care and service providers ${ }^{2}$ regarding the ways in which they provide information to PHAs and their friends/family members. During the PHA and friend/family member interviews, a network solicitation and chain-referral (also called "snowball") recruitment procedure (Erickson, 1979; Wasserman \& Faust, 1994) was used to delineate their HIV/AIDS information networks. By focusing my research on the perspectives of different actors who rely on HIV/AIDS information through social networks, I attempt to extend our collective understanding of the deeply interactive, socially embedded nature of information exchange.

\section{Individual Information Behavior and HIV/AIDS}

From the point of view of information seekers, information is something that helps them make sense of their situations, assists them in dealing with challenges that they face (Dervin, 1983), and can be conceptualized as "that sense created at a specific moment in time-space by one or more humans" (Dervin, 1992, p. 63). In other words, information is anything that "helps" information seekers (Dervin, 1992; Dervin \& Fraser, 1985; Harris \& Dewdney, 1994), acting as a bridge for people as they move beyond gaps in understanding brought about by their present situation (Dervin, 1992).

Dervin (1983) argues that information needs can be understood as situational, with a person's situation the greatest predictor of his or her information needs. Harris and Dewdney (1994) also contend that information needs arise from the help-seeker's situation, with any need for help or information being situationally and contextually-based. As a situation, managing HIV/AIDS presents a series of key treatment decisions and areas of uncertainty (Brashers, Neidig, Russell, Cardillo, Haas, Dobbs, et al., 2003) that may spark specific questions and information seeking. Examples of these situation-bound decisions include whether to start treatment, choosing treatments, how treatment is working and whether to change treatments (Health Canada, 2000). Relatedly, Huber and Cruz (2000) found that PHAs' most important information needs are directly related to the situation of dealing with their illness: drug, medical, treatment and wellness information. PHAs also have significant needs for practical and experience-based information regarding these topics (Sandstrom, 1996).

\footnotetext{
${ }^{2}$ Health care and service provider participants occupied formal caregiving roles vis-à-vis rural dwelling PHAs and friends/family members. These provider participants included: physicians; nurses; health social workers and psychologists; AIDS organization support workers; addictions workers; housing and income support workers; alternative health care providers; and individual members of several other health professions and community service sectors.
}

Friends/family members of people with serious illnesses may also need information to help them deal with their loved one's health status and practical care needs (see, for example, Feltwell \& Rees, 2004; Fitch \& Allard, 2007; Mason, 2008; Rees \& Bath, 2000). Similarly, friends and family members of PHAs report that they need information that arises from their situations, such as basic information about HIV treatment and prevention (Health Canada, 2000).

Information seeking behavior can be defined as, "the purposive seeking of information as a consequence of a need to satisfy some goal." (Wilson, 2000, p. 1) As has been found in people with other health conditions (see, for example, Chen \& Siu, 2001; Raupach \& Hiller, 2002; Raynor, Savage, Knapp, \& Henley, 2004), PHAs rely heavily on consultation with other people, such as their personal physicians, when seeking HIV/AIDS information (Health Canada, 2000; Hogan \& Palmer, 2005; Huber \& Cruz, 2000). Additionally, PHAs value interaction with their peers as a source of information (Adelman \& Frey, 1997; Brashers et al., 2000; Sandstrom, 1996; Taylor, 2002), and they may also come across peer-based information "incidentally" (Williamson, 2005) in the context of support groups for HIV-positive people (Brashers, Neidig, \& Goldsmith, 2004; Brashers et al., 2000; Sandstrom, 1996; Spirig, 1998) or through volunteering with AIDS service organizations (ASOs) (Brashers, Haas, Neidig, \& Rintamaki, 2002). Like PHAs, friends and family members of PHAs consider physicians, friends/family and PHAs to be important sources of HIV/AIDS information (Health Canada, 2000).

While existing research offers insights into the importance of interpersonal sources for HIV/AIDS information acquisition, little is known about how this behavior happens interactively within social life. Through the present research, I aim to deepen understanding of these phenomena by attending to the perspectives of multiple actors within HIV/AIDS information networks in rural Canada.

\section{Collaborative Information Behavior}

Although the majority of information behavior studies to date have considered the information behavior of individuals, it is increasingly recognized that information behaviors may also be undertaken by groups, particularly as a part of collaborative work and learning (Foster, 2006). "Collaborative information behavior" can be defined as "an activity where two or more actors communicate to identify information for accomplishing a task or solving a problem" (Talja \& Hansen, 2006, p. 114). Talja and Hansen (2006) argue that collaborative information behavior is a broad category which may include both "collaborative information seeking and retrieval," which focuses on acquiring new information, and "information sharing," which involves communicating information that has already been acquired (p.114). However, they also argue that in practice, these behaviors may overlap or coincide (Talja \& Hansen, 2006). Similarly, Hertzum (2008) contends that models of collaborative information behavior should focus attention both on information seeking 
and sharing within groups, since information sharing helps collaborators to develop and maintain "common ground," defined as a set of shared understandings that facilitate collaborative work. According to Hansen and Järvelin (2005), collaborative information activities may focus on either a) documents, such as when people create or use documents together; or b) human beings, where people seek advice or expertise from others (pp. 1110-1111). In accordance with these models, I consider both collaborative information seeking and sharing in this research, as well as activities that focus both on documents and people.

Collaborative information seeking and retrieval practices have been studied in varied workplace contexts, such as health care facilities (Reddy \& Jansen, 2008; Reddy \& Spence, 2008), the military (Prekop, 2002; Sonnenwald \& Pierce, 2000), government (Hansen \& Järvelin, 2005) and design teams in companies (Bruce, Cleal, Fidel, \& Pejtersen, 2004; Bruce, Fidel, Pejtersen, Dumais, Grudin, \& Poltrock, 2003; Poltrock, Grudin, Dumais, Fidel, Bruce, \& Pejtersen, 2003; Sonnenwald \& Lievrouw, 1997). Collaborative information behavior has also been examined in the context of academic work (Hyldegard, 2006, 2009; Twidale, Nichols, \& Paice, 1997).

Fidel, Petjersen, Cleal, and Bruce (2004), Reddy and Jansen (2008), and Reddy and Spence (2008) argue that people may seek information collaboratively in the workplace for a number of reasons, such as: one's own lack of expertise in a particular area or a need for tacit knowledge; information traits, such as lack of immediate accessibility or ambiguity; and decision-making with wide organizational implications.

Collaborative information seeking is deeply embedded in work practices (Foster, 2006; Reddy \& Spence, 2008), and many collaborative information behaviors have been documented in prior research. Such documented behaviors include: discussing and agreeing upon shared information needs (Poltrock et al., 2003); joint searching (Twidale, Nichols, \& Paice, 1997); delegated or coordinated searching (O’Day \& Jeffries, 1993; Poltrock et al., 2003; Prekop, 2002; Twidale et al., 1997); asking questions and giving answers (Hansen \& Järvelin, 2005; Poltrock et al., 2003; Prekop, 2002; Reddy \& Spence, 2008; Twidale et al., 1997); advertising interest in information (Prekop, 2002); using information systems and sources during collaborative, problem-solving conversations (Crabtree, Twidale, O’Brien, \& Nichols, 1997; Reddy \& Jansen, 2008; Sonnenwald \& Pierce, 2000); producing prototypes for feedback (Poltrock et al., 2003); and holding or attending group meetings (Poltrock et al., 2003). Flowing from this research, a growing number of scholars have criticized the systems design paradigm that treats users solely as individuals, advocating instead the expanded development of systems that support collaboration (Foster, 2006; Hansen \& Järvelin, 2005; Poltrock et al., 2003; Reddy \& Jansen, 2008; Sonnenwald \& Pierce, 2000; Twidale et al., 1997).

As a type of collaborative information behavior, information sharing can be understood as a collaborative and interactive process (Talja \& Hansen, 2006, p. 114). The interactive process of information sharing "incorporates both active and explicit and less goal oriented and implicit information exchanges" (Talja \& Hansen, 2006, p. 114). Talja and colleagues $(2002 ; 2006)$ argue that people share information as much as they seek it. Indeed, studies of scholars in different academic fields have, for example, found that scholars frequently share information that they find with others (Erdelez \& Rioux, 2000; Twidale et al., 1997). Workers may also share information through behaviors such as proactively recommending or forwarding information or contacts to their colleagues (O’Day \& Jeffries, 1993; Poltrock et al., 2003; Prekop, 2002; Sonnenwald \& Pierce, 2000; Twidale et al., 1997); sharing documents and document histories with team members (Hansen \& Järvelin, 2004; O'Day \& Jeffries, 1993); creating documents or records of searching for use by others (Hansen \& Järvelin, 2004; O’Day \& Jeffries, 1993); and archiving information in group repositories (O'Day \& Jeffries, 1993). It has also been suggested that information sharing in workplaces and scholarly settings may serve a variety of social and organizational purposes (see, for example, Davenport \& Hall, 2002; Fidel et al., 2004; Talja, 2002).

Talja and Hansen (2006) argue that everyday life collaborative information behavior is an understudied area, with only a few studies to date addressing these concerns. In one such study, McKenzie (2003) found that some pregnant women received information "by proxy," or at the initiative of another person. Additionally, Pettigrew's (1999) research within foot clinics for senior citizens included the insight that people who gather together for social or service-oriented purposes may share information spontaneously with one another. Rioux (2005), Rieh (2004), and Abrahamson, Fisher, Turner, Durrance, and Turner (2008) have also demonstrated that, in an everyday life context, people may look for information for others on the Internet. In an HIV/AIDS context, Brashers et al. (2004) also found that friends and family members of PHAs may help them find information and discuss results of searches with them. While this research helpfully begins to describe information sharing in everyday life, much remains to be understood about collaborative information behavior. This paper contributes to the understudied field of everyday life collaborative information behavior by examining the ways in which PHAs and their friends/family members acquire and share HIV/AIDS information through their social networks.

\section{Social Network Analysis and Information Behavior}

Social network analysis is an empirical method in which social structure is viewed as a product of patterns of relationships between people and collectivities (Degenne \& Forsé, 1999). Using this approach, networks are arrived at empirically and inductively based on linkages among actors that are modeled into networks using quantitative methods (Scott, 1991; Wasserman \& Faust, 1994).

In library and information science research, there is a long-standing interest in use of social network analysis to investigate information behavior in a variety of settings. 
For instance, this framework has been applied to fields such as scholarly communication (e.g., Crane, 1972; Crawford, 1971; Kronick, 2001), workplaces (e.g., Allen, 1977; MacKenzie, 2005), online education (e.g., Haythornthwaite, 1998a, 2000), and everyday life information behavior (e.g., Hersberger, 2003; Jeong, 2004; Pettigrew, 2000). This research has focused on mapping communication channels for gaining access to information in networks (see, for example, Haythornthwaite, 1998b); identifying structural features of networks, such as the presence of central actors (see, for example, Crane, 1972) and bridges/boundary spanners (Agada, 1999; Allen, 1977; Metoyer-Duran, 1993; Thompson, 1996); and studying the roles of strong and weak ties in acquisition of new information (see, for example, Bian, 1997; Granovetter, 1973; Pettigrew, 2000; Yakubovich, 2005).

The above studies describe the role of network structures in access to information, yet they do not focus particular attention on how people gain information from their networks. Nevertheless, as Haythornthwaite (1996) argues, networks can affect information access in different ways, such as through what she terms information "exposure," "legitimation," and "opportunities." In my research, I aim to develop a deeper understanding of these processes by using Haythornthwaite's (1996) largely unexplored concepts as a starting place for analysis of information network dynamics, as well as Talja and Hansen's (2006) collaborative information behavior model.

\section{Methods}

\section{Data Collection}

One hundred and fourteen individual, in-depth, semistructured interviews were conducted with residents of three rural regions of Canada: the Kootenays (British Columbia), rural Newfoundland, and Huron-Perth (Ontario). Rural interviewees included: PHAs, their friends/family members, and health care/service providers. Additionally, PHAs and friends/family members identified some urbanbased, HIV specialist health care/service providers as important members of their HIV/AIDS information networks. Urban providers identified in this way were also invited to participate in provider interviews.

Fifty-seven initial interview participants were recruited through collaborating health clinics and social service agencies. Because of the intensive nature of interviews, interview guides were used (Brenner, 1985), with different guides for each participant type. In keeping with the qualitative approach to interviewing, interview questions were openended (Creswell, 2003) and elicited responses about participants' behavior/experiences, opinions/values, feelings, and knowledge (Patton, 1990). The interviews focused on: interviewees' experiences with HIV/AIDS; how they locate and use HIV/AIDS information; the nature of HIV/AIDS information networks in rural areas; and how these networks work. Each in-depth interview was conducted in a place that the participant identified as safe for them. Interviews lasted from
1-3 hours. Participants were given the option to be audiorecorded, or to have the interviewer take handwritten notes only. In recognition of their participation, Huron-Perth participants were offered a $\$ 20$ grocery voucher and Kootenay participants were offered $\$ 20$ honorarium. The Institutional Review Board in Newfoundland did not permit the use of incentives for participation. Interviews were conducted from May 2005 to August 2006.

In support of chain-referral recruitment, network solicitation also took place as a part of the interviews with PHAs and friends/family members. Participants' networks were elicited using multiple "name generator"-type questions to draw out the names of actual or potentially informative people (van der Poel, 1993). Each interview concluded with a confirmation of the participants' information networks, and a request for participants to nominate and recruit other participants located within their region. Accessible recruitment materials were given to PHAs and network members for their use in recruiting their nominees. As a result of this chain-referral recruitment procedure, 57 additional interviewees were recruited. The final sample included many pairs and clusters of interconnected individuals, and thus permitted analysis of multiple perspectives regarding the same information exchange behavior. For the interviews, ethical approval was obtained at the University of Western Ontario, the University of Victoria, and Memorial University of Newfoundland.

\section{Data Analysis}

Interview data were analyzed qualitatively and compared to Haythornthwaite's (1996) concepts of network-based (or "network-mediated") information processes and Talja and Hansen's (2006) collaborative information behavior framework. These conceptual frameworks formed the initial codebook, although emergent categories were also generated inductively. In keeping with the micro-sociological interactionist tradition, the basic unit of study employed in interview analyses was the "interaction"- - a type of dynamic, situated, ongoing activity between individuals (Charon, 1998) who were identified as members of participants' HIV/AIDS information networks. Analyses also involved attention to the role of documents in these interpersonal interactions. A constant comparison analytical approach (Glaser \& Strauss, 1967) was used to examine both emergent results and to assess the viability of these conceptual frameworks. Categorization and open coding (Strauss \& Corbin, 1998) of data was facilitated by the use of NVivo qualitative data analysis software. Memos and diagrams were used to represent the conceptual relationships that developed among emergent categories (Strauss \& Corbin, 1998).

\section{Results}

Demographic Characteristics of Interview Participants

In total, 114 participants were interviewed across three geographic regions, including 34 PHAs and 28 of their 
TABLE 1. Final sample by participant type.

\begin{tabular}{lcrr}
\hline & Kootenay region & Rural Newfoundland & Huron-Perth \\
\hline Category & & & \\
People living with HIV/AIDS (PHAs) & 8 & 10 & 16 \\
Friends/family members of PHAs & 8 & 6 & 14 \\
Health and social service providers & 15 & 13 & 24 \\
Total & 31 & 29 & 54 \\
\hline
\end{tabular}

TABLE 2. Demographics of sample: PHAs and friends/family members.

\begin{tabular}{|c|c|c|c|c|}
\hline & Kootenay region & Rural Newfoundland & Huron-Perth & Total \\
\hline \multicolumn{5}{|l|}{ Gender } \\
\hline Male & 8 & 5 & 12 & 25 \\
\hline Female & 8 & 11 & 18 & 37 \\
\hline \multicolumn{5}{|l|}{ Age (estimate) } \\
\hline $18-29$ & 0 & 0 & 3 & 3 \\
\hline $30-39$ & 2 & 9 & 4 & 15 \\
\hline $40-49$ & 7 & 4 & 6 & 17 \\
\hline $50-64$ & 6 & 1 & 11 & 18 \\
\hline 65 or older & 1 & 2 & 5 & 8 \\
\hline Unknown & 0 & 0 & 1 & 1 \\
\hline \multicolumn{5}{|l|}{ Race/ethnicity } \\
\hline Native American descent & 3 & 0 & 0 & 3 \\
\hline Hispanic/Latin American descent & 0 & 0 & 2 & 2 \\
\hline White/European descent & 13 & 16 & 27 & 56 \\
\hline Unknown & 0 & 0 & 1 & 1 \\
\hline \multicolumn{5}{|l|}{ Sexual orientation } \\
\hline Gay/lesbian/bisexual & 4 & 4 & 8 & 16 \\
\hline Heterosexual & 11 & 12 & 21 & 44 \\
\hline Unknown & 1 & 0 & 1 & 2 \\
\hline
\end{tabular}

friends and family members (Table 1). In addition, 52 health care and service providers were interviewed as key informants. ${ }^{3}$ All participants were tied to at least one other interview participant, with the interconnections between them determined inductively through the aforementioned recruitment procedures. Overall, there were 260 ties between interview participants, including: 101 ties involving PHAs and friends/family members; and 159 ties between health care/service providers and PHAs or friends/family members. Network size and composition varied among participants, such that some participants were linked to several friends/family member participants in the sample, while six PHA participants and four friends/family members ${ }^{4}$ were

\footnotetext{
${ }^{3}$ As key informants, health care/service providers were not asked to describe their interactions with specific people; rather, they commented generally about how they gave information to their clients or patients, who were PHAs and friends/family. Hence, the majority of specific information about client/patient-provider interactions came from PHAs and friends/family members themselves, with providers giving more general information about such interactions. As such, providers may have also described their interactions with some PHAs or friends/family members who were not in the sample.

${ }^{4}$ These four family members/friends of PHAs were recruited through health care/service providers rather than chain-referral recruitment. Three were family members of deceased PHAs, and one was related to a PHA who lived outside of the area.
}

tied only to health care/service provider participants. More extensive data were thus available regarding participants who were tied to more other study participants, thus potentially skewing findings toward the information behavior of such individuals. Nevertheless, the aim of this research was not to generalize behavioral patterns to a population; rather, in keeping with the goals of qualitative research (Creswell, 2003), this study generated descriptive categories that reflected the range of participants' experiences. As such, the trustworthiness of these data is strengthened by the durability of findings across a sample with diverse networks, including both the most and least connected.

Of the 34 PHA interview participants, roughly equal proportions of men and women participated in interviews, although there were slightly more male PHA participants in the Kootenays and slightly more female participants in rural Newfoundland (Table 2). This broadly reflects the cumulative gender demographics of HIV infection in these regions (BC Centre for Disease Control, 2006, p. 16; Ratnam, Hogan, \& Hankins, 1996). Across regions, the majority of participants were between the ages of 30 and 49, and most were also of white/European descent. Roughly $40 \%$ of PHA participants in all regions identified as gay, lesbian, or bisexual. Most of the 28 family member and friend participants were female, heterosexual, and 50 years or older. The Huron-Perth sample in particular was older (Table 2). Family members and 
friends largely had the same racial or ethnic backgrounds as the PHA in their lives.

\section{Acquiring and Sharing Network-Mediated HIV/AIDS Information}

As has been reported elsewhere (Veinot, Harris, Bella, Rootman, \& Krajnak, 2006), because of limited communitywide discussion about the disease, merely going through life in a rural community would not necessarily lead to being informed about HIV/AIDS. Instead, specific relationships with HIV/AIDS-knowledgeable people affected by the disease were key drivers for information acquisition and sharing regarding the disease in study communities. The importance of interpersonal information exchange may have been heightened by the fact that only one-half of PHAs and friends/family members had ever used the Internet to look for HIV/AIDS information, with only two-thirds reporting that they had home Internet access.

Thus, participants argued that the likelihood of being a part of discussions or dialogue about HIV/AIDS was highly contingent on who one interacted with, as this PHA asserted, ". . . it depends on the individuals that you're talking to really." With network ties thus providing a potentially rare conduit for access to HIV/AIDS information for rural dwellers, it is all the more important to understand how these networks worked. In this paper I show that participants shared and acquired networkmediated information about HIV/AIDS through five network dynamics: joint information seeking, tag team information seeking, network-mediated information exposure, networkmediated opportunities, and network-mediated legitimation.

Joint information seeking. "Joint information seeking" involved those collaborative information seeking interactions where two people sought information, and did so together on a voluntary basis. As is shown in Figure 1, these interactions

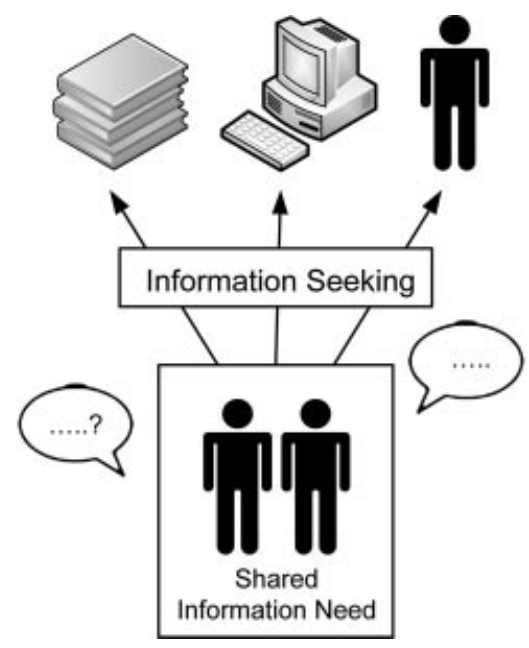

FIG. 1. Joint information seeking. Interactions in which two people sought information together in order to satisfy a shared information need. The interaction involved conversation regarding information sought or gained. involved two people with a shared HIV/AIDS information need (as demarcated by their presence in the same box), simultaneously looking for information from print sources, the Internet, and/or other people. As is also shown in Figure 1, these activities were usually accompanied by back-and-forth conversation regarding information sought or gained; such conversation often involved a dynamic interplay of questions and statements. Examples of these activities among study participants included: two people searching the Internet and reviewing retrieved documents together, a group of friends of a PHA attending an occasional HIV/AIDS workshop, PHAs attending intermittent volunteer meetings, or PHAs and friends/family going to health care appointments together. Such shared information seeking, particularly via the Internet, was often used as a conversational resource regarding the shared information need. For example, this mother of a PHA said,

"Rick ${ }^{5}$ and I were running around like crazy in the beginning just trying to find out some information. ... [h] e was really worried that he had tongue cancer, that's what started it.... [h]is tongue was all split, and of course you know you look up stuff on the Internet, and so we were looking at his tongue and everything else.... We sat down with the pictures and, I'm looking at his picture and he's looking in the mirror,... so we looked up lots together."

Similarly, this partner of a PHA said that they regularly look for information on the Internet together,

"... we use the Internet a lot to try to figure out what's working for others and how we may improve her situation if possible...what type of medication she's taking, what other people's experience with that is, who is having success, who's not. Yeah, the side effects of the meds. What she can eat. What she can't eat and this type of thing."

Participants also described joint information seeking with health care and service providers, such as in this case where a much-appreciated physician learned "along with" a newly diagnosed patient,

"I was my doctor's first HIV patient ... the doctor I was working with was basically uninformed ... for, at least 5 days I just didn't know what to do. I just figured that was it, I've got AIDS, I'm dying ... [but] he's just been great...[h]e's just, you know he's learning too. He's getting the books too, and he's just been absolutely great ... he's been so great in learning the step by step everything with me...."

Joint information seeking seemed to have important interpersonal effects, with participants retrospectively emphasizing the emotional support exchanged through discussions. For example, Rick's mother said that she thought that looking on the Internet together was helpful because, "I think it was

\footnotetext{
${ }^{5}$ Names have been changed to protect participant confidentiality.
} 


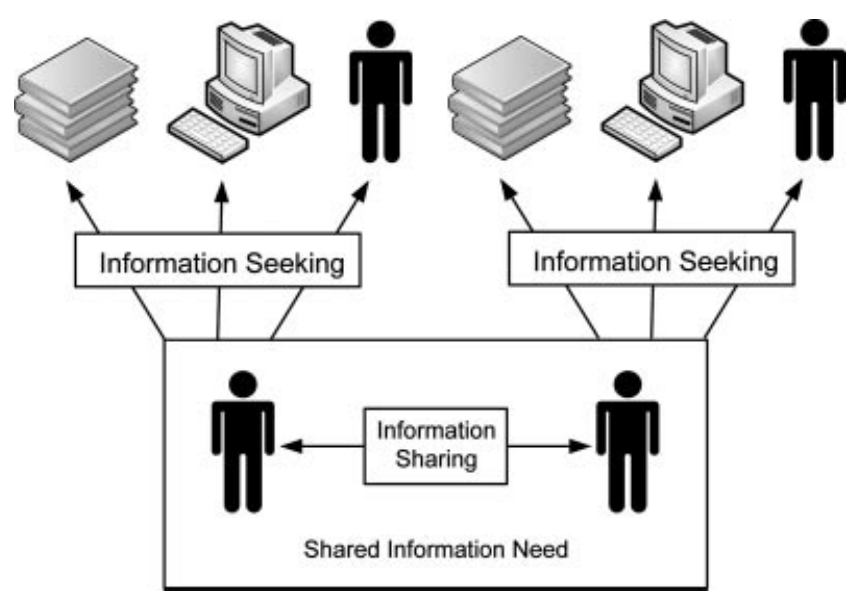

FIG. 2. Tag team information seeking. Interactions in which two or more people with a shared information need looked separately for information and then shared what they found.

important for Rick to have somebody to talk to." Similarly, Rick himself described his mother as,

“... really, really, really supportive.... You know, she's seen me trying in life and realized that I keep stumbling along [laughs]. But yeah, she's really easy to talk to as well."

Thus it appears that joint information seeking could be an experience that participants found to be emotionally supportive, and may have even helped supportive relationships to develop further. However, in some cases PHAs felt imposed upon by others through joint information seeking on the Internet. For example, a PHA said that his family member with whom he searched the Internet was domineering in decision-making related to his health, and yet another felt overwhelmed by her loved one's intense interest in searching for HIV/AIDS information together.

Tag team information seeking. Another form of collaborative information seeking was "tag team information seeking," which, as shown in Figure 2, involved people with a shared information need (as per their presence in the same box) looking separately for information via print sources, the Internet, or other people. Importantly, because these activities were undertaken separately, as Figure 2 shows, information seeking was followed by participants sharing what they had found with their network members. Like joint information seeking, these activities were voluntarily undertaken; however, these activities were not simultaneous, but loosely coordinated between people, if they were coordinated at all. The distinction between joint and tag team collaborative information seeking was not rigid, though, since some of the same people engaged in both joint and tag team information seeking at different times, or moved back and forth between these behaviors.

Some participants engaged in tag team information seeking in order to triangulate information sources, such as when two people in communication would ask their doctors the same question in order to, as this family member said, "...compare notes to make sure we were both getting the same information...." Tag team information seeking also took place as a network-wide learning exercise, such as when members of a network used the Internet independently and then discussed the results of their information seeking. As this family member of a PHA said,

\begin{abstract}
"I think we've all learned together ... in the very beginning when nobody knew much; we didn't know much about it even, so we all got learning.... And we're all on the computer ... at night so they all, they'll go online and they'll check this one out, this site out or, so they did a lot of that too, studying on line ... like whatever any of us learned...."
\end{abstract}

Generally, participants felt that their friends and family members who sought information independently and brought results back to them were supportive, as this PHA said of her sister who brought information to her,

"I think my biggest supporter where HIV is concerned over the years, has been my sister ... she's been my biggest champion, when she found out that I had HIV, she went all over the place getting all these pamphlets from the Health Unit and everything and reading all this stuff...."

Hence tag team information seeking was seen as an important way of obtaining new HIV/AIDS information and as a marker, and manifestation, of emotional support as people faced HIV/AIDS together.

Network-mediated information exposure. At times, network members were "exposed" to HIV/AIDS information by others. In other words, it was "present[ed] to view" or "put forth" to these network members (Oxford English Dictionary, 1989a). The concept of network-mediated exposure to information refers to those many incidents where participants did not actively seek information, but social proximity exposed them to HIV/AIDS-related information in ways that were either human-related or document-related. As shown in Figure 3, in such situations, participants gained unsought information (as designated through unidirectional arrows pointing to the information recipient) through interaction with another network member, or with documents that the other network member had. In the present research, then, participants who acquired information in this way did so simply by virtue of listening to, looking at, or interacting with, people and documents in their social worlds. As such, the information was something that was already available in the network, rather than being sought collaboratively by network members.

As a part of the network-mediated exposure interactions that I describe, there was a source, or "agent" (McKenzie, 2003) of the information, a person who presented information, or brought it forth; and another person, who experienced the interaction as "exposure." This source or agent, as depicted in Figure 3, exposed the other person to information 


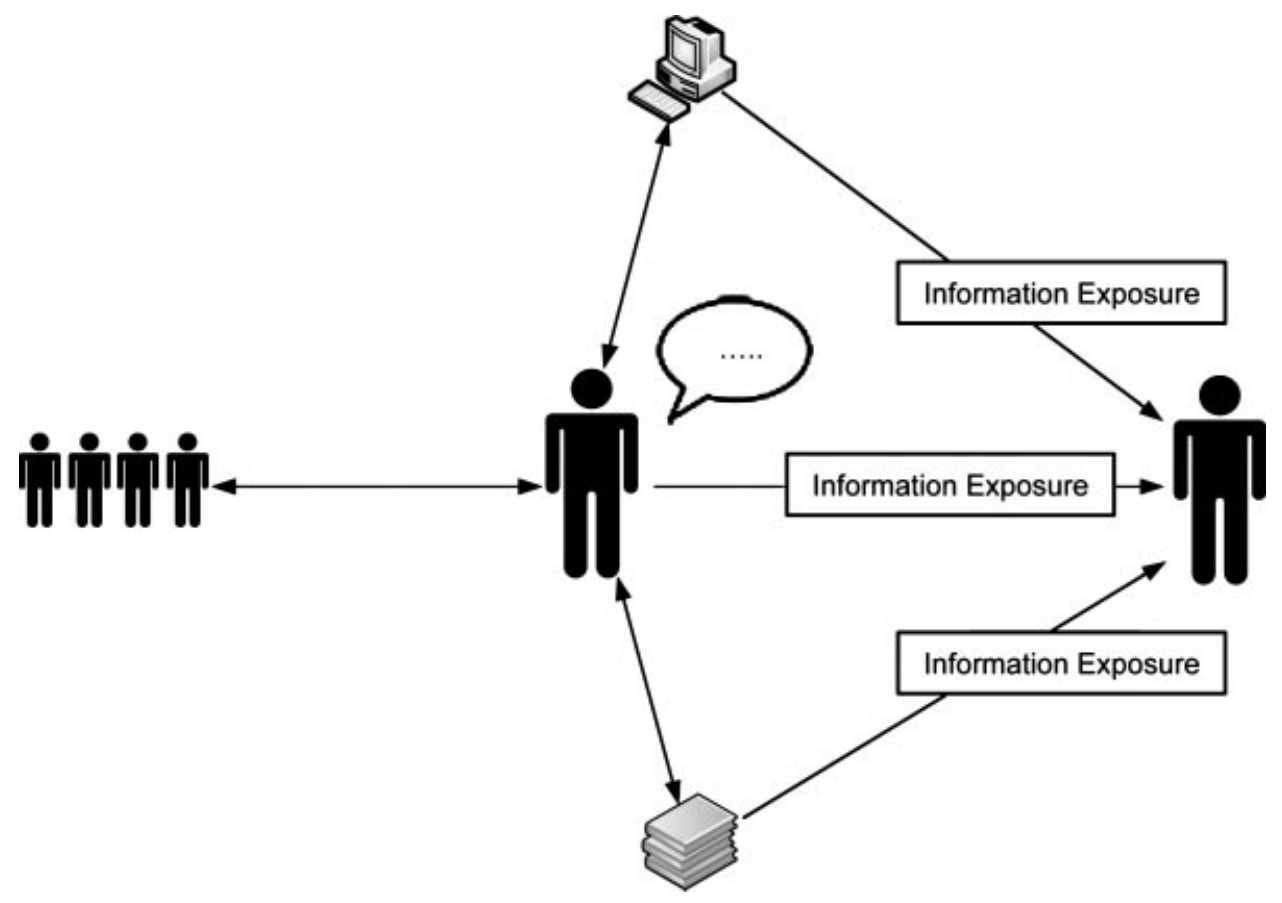

FIG. 3. Network-mediated information exposure. Interactions in which participants did not actively seek information, but participants gained information through interaction with another network member, or with documents that they had, and also relied upon.

TABLE 3. Accessing network-mediated HIV/AIDS information.

\begin{tabular}{|c|c|c|c|c|}
\hline PHAs and friends/family members & Kootenay region & Rural Newfoundland & Huron-Perth & Total \\
\hline $\begin{array}{l}\text { Has received HIV/AIDS information from another } \\
\text { person that he/she didn't ask for }\end{array}$ & $9(56.20 \%)$ & $4(25.00 \%)$ & $18(60.00 \%)$ & $31(50.00 \%)$ \\
\hline Has given information/advice to someone else & $16(100.00 \%)$ & $12(75.00 \%)$ & $24(80.00 \%)$ & $52(83.87 \%)$ \\
\hline
\end{tabular}

conversationally, or by actively or passively sharing his/her print or electronic documents. As shown by the bidirectional arrows in Figure 3, the information giver also relied upon some of these documentary information sources, as well as obtaining information from other people which they subsequently shared. From the perspective of the initiator, "informing" or "helping" another person could be "active and explicit or less goal-oriented and implicit" (Talja \& Hansen, 2006, p. 114). Where explicit goals were present for the information giver, they were sometimes, but not necessarily, directed to "informing." Rather, from the perspective of the people providing the information, they were at times trying to inform the other person, but at other times they were seeking emotional support or tangible aid, chatting about their interests, or updating a loved one about their activities. Additionally, when PHAs kept HIV/AIDS-related documents or Internet bookmarks within a living space that they shared with others, their cohabitants were exposed to documents that informed them about the disease within their living environments.

To illustrate the prominence of such network-mediated exposure in information networks, Table 3 shows that $25-60 \%$ of PHAs and friends/family members across regions had received information about the disease from another person without asking for it, incidents that often matched what I term network-mediated exposure. Additionally, more than three-quarters of participants in each region indicated that they had given information or advice about HIV/AIDS to someone else. Where this research included both the givers and receivers in the sample, I was able to determine that these "information giving" episodes included what I have called exposure.

Network-mediated information exposure with family members and friends. Generally, network-mediated information exposure through family/friend relationships ${ }^{6}$ occurred more for participating friends/family members of PHAs than for PHA participants themselves. For example, upon the disclosure or major illness of a PHA loved one, friends/family members reported that they were given a great deal of information about the disease, particularly by the PHA

\footnotetext{
${ }^{6}$ Among the 101 PHA-friend/family member ties among participants, there were 43 ties between PHAs and their HIV-negative friends/family members, 43 ties between PHAs who were friends/family members of one another, and 15 ties between HIV-negative friends/family members of PHAs.
} 
they knew. Commonly, HIV/AIDS transmission was a focus of these initial discussions, with PHAs offering information at their own initiative as a part of disclosure: “... she basically told us ... [how] it is transmitted ... she is the one who educated pretty much everybody that she told." From the perspective of the receivers, this was a form of information exposure for them and it was "active and explicit" (Talja \& Hansen, 2006, p. 114).

In the long term, living in close proximity to PHAs exposed friends/family to HIV/AIDS information, much of it acquired without intent, and exchanged in ways that were "less goal directed and implicit" (Talja \& Hansen, 2006, p. 114). For example, friends and family members described many instances where they learned about HIV/AIDS when their PHA loved ones sought emotional support from them. In those exchanges, PHAs shared their experiences and feelings, seeking a sympathetic ear, but their friends/family members gained information at the same time, as this close friend described,

“... I haven't even had to think about getting information about HIV ... since [she] was diagnosed I get it whether I want it or not. . .that's what I do. I listen. That's the way I support...."

Similarly, a PHA gained emotional support from her spouse about her painful experiences of antiretroviral drug side effects, and in so doing, she gave him information about what it is like for her to live with treatment. This conversation, and others like it, meant that, as he said, she is his "primary" source of information about the disease. In these exchanges, then, the two participants gained different forms of help from the same interaction-the information giver gained emotional support and the other information. Yet from the perspective of one party, they were exposed to information without looking for it.

Friends/family members of PHAs were also exposed to HIV/AIDS information when PHAs became involved in HIV/AIDS volunteerism and/or activism. In such cases, PHAs' passion and enthusiasm for educating others about the disease spilled over into their personal lives such that they often told others what they had learned, or about their educational activities, without being asked. These types of exchanges tended to be active and explicit, but not particularly goal-oriented, since the person "telling" the information did not necessarily set out to "inform" their loved one-it was simply a matter of conversation, as this family member said, "she's pretty talkative ... anything I need to know, like she's probably already told me. ..." Another family member said that her PHA relative regularly told her about things she learned through her activism,

“... [she] is sitting on the committees and things like that ... they're always coming up with different things like say what medications and things like that and she usually keeps informed."

Additionally, PHA volunteer-activists often obtained and collected HIV/AIDS-related documents, and these were readily available for family members and friends who lived with them, as this family member described,

". . .he brings home information, like magazines or stuff like that, he always brings them home and I read it too."

Overall, then, in keeping with Talja and Hansen's (2006) model, these examples of interactions in which friends/family members were exposed to human- and document-related HIV/AIDS information included the "active and explicit" and the "implicit and less goal-oriented." Additionally, they included interactions with goals that ranged from fuzzy to explicit. Clearly, there was a significant variety of paths to network-mediated HIV/AIDS information exposure for the friends and family members of PHAs.

PHAs who had close relationships with other PHAs also reported being "exposed" to a great deal of information related to the disease through these ties. In particularly close relationships, PHAs said that they gained information through monitoring their loved one's health, daily conversations, shared activities, and, at times, informal care giving, as this PHA said of his relationship with his PHA spouse and friends, "... .we've learned a fair bit in the last 14 years of dealing with ourselves, our friends...." Close relationships between PHAs also meant that PHAs were exposed to the availability of documents that other PHAs had gathered and placed in their shared environments, such as book collections, magazine subscriptions, and Website bookmarks. These exchanges were generally "implicit" and "less goaloriented” (Hansen \& Järvelin, 2005; Talja \& Hansen, 2006), yet gave them resources for use in their own information seeking, as this PHA described, "... he gets that Newsletter ... so-I read his mail [laughter]."

Thus, much human-related HIV/AIDS information exchange between PHAs with close ties to one another was woven into the activities of daily life. A great deal of this acquired information was implicit and not focused on the goal of information exchange. Rather, it was gained through a range of experiences, and could be absorbed simply by going through life when PHAs were close to one another. Hence, this type of network-mediated exposure was implicit and oriented toward a plurality of goals, and participants were exposed to HIV/AIDS information because of their social proximity to the cares and concerns of people affected by the disease. Such peer-based information exchange was often experienced as supportive at the same time as being informative, such as for a PHA who gained hope from long-term survivors of the disease.

For PHAs, being in social contact with acquaintances or casual friends who were also PHAs could also be highly informative, and much of the information exchange that took place in such circumstances was, as Talja and Hansen (2006) described, implicit and not particularly goal-oriented. PHAs who knew others who had died of AIDS developed expectations about the prognosis of the disease in the absence of effective treatment. PHAs grew to fear HIV drugs because of potential, visible side effects that they saw among their 
peers; and one PHA was able to partially answer her question about how long people could live with HIV/AIDS by observing other people at her HIV clinic, “....there's a lot of people go to the doctors ... they look like they've had it for ages." In situations in which there were several PHAs present, some participants also said that they learned about the disease and its treatment by listening in on others' conversations,

"I overhear people talking about it, and it might be all of a sudden. Like they hear that Glaxo Wellcome has a new medication, and about their clinical trials. So I perk up my ears ...."

In an "active" and "explicit" manner, PHA acquaintances also engaged in "document-based" information sharing episodes. In particular, e-mail and face-to-face contact between PHAs facilitated the proactive sharing of HIV/AIDS-related documents between people who did not share a specific information need, as this PHA described,

" . . . a friend will send you something. If I come across something I do the same thing, fire it off to friends in case they want to see it. So yes, information these days comes from all different directions."

Accordingly, relationships with PHAs emerged as particularly information-rich ties, regardless of how close the relationships were. Moreover, as per Talja and Hansen's (2006) model, network-mediated exposure-based interactions between PHAs involved documents and humans, could be explicit or implicit, and varied in the extent to which they were goal-driven in general, or driven by goals of information sharing in particular.

Network-mediated information exposure with health care/service providers. As would be expected, exposure to information commonly occurred through clinical interactions with health care and service providers. In such exchanges, providers volunteered information to their clients/patients as a part of a wider interaction. PHAs also mentioned being exposed to information about ASO programs and offerings, or about other services available to them, through mailings from, or conversations with, their ASO support workers or other professionals.

Interestingly, this provider-initiated information exposure is something that a few participants had grown to rely on to a significant extent. Trusting in their health care providers to expose them to needed information, several PHAs who were not interested in seeking information on their own said that they felt that their health care providers would draw their attention to it if there was something that they should know. Hence, their key strategy for gaining access to relevant HIV/AIDS information was to maintain ties with HIV-knowledgeable providers who would tell them when they needed to know something, as these PHAs described,

"If there's something that needs to be told to me I'm sure that Dr. Collins and Jennifer will address it, and they will inform me if there is something new...."

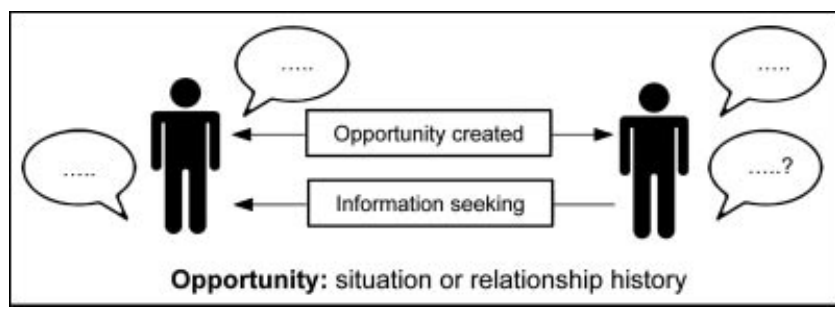

FIG. 4. Network-mediated information opportunity. Under socially opportune conditions created through an interaction, one network member sought information from another by asking questions or requesting documents.

"I don't go out of my way to search for things ... I figure that there are people around me to help, and they will give me what I need, and they're the most up to date on things anyways."

\section{Network-Mediated Information Opportunity}

Asking other people for information in relation to a stigmatized illness can be a difficult thing. HIV/AIDS information seeking may involve being vulnerable to another person and possibly losing esteem in their eyes. As well, it carries a risk that needed support will not be available. Asking for information about the disease may also present the possibility of uncomfortably treading upon another person's privacy or personal sensitivities. In the context of such challenges, HIV/AIDS-related information seeking through social networks often took place when there was a network-mediated "opportunity" to seek HIV/AIDS information, or "a time, condition, or set of circumstances permitting or favorable to a particular action or purpose" (Oxford English Dictionary, 1989b). Thus, the time, social conditions, or relational circumstances were "right" for it from the point of view of participants. As Figure 4 shows, two people helped to create such opportune situations or relational contexts through their interactions, a shared context which is designated by the box surrounding the activity. Following interactions establishing this shared context, Figure 4 shows that one participant sought information from another by asking and answering questions, or asking for and receiving documents, as a part of this flow of interaction. The information sought was already available from network members, and thus was different from collaborative information seeking, where network members sought information together. This concept thus differs substantially from Haythornthwaite's (1996) concept of "information opportunities," which refers to the ability of network members to control other network members' access to information. Drawing from Talja and Hansen's (2006) model, network-mediated opportunity-based interactions between PHAs involved documents and humans, and were largely explicit, although they often began after the implicit establishment of opportunity. These interactions varied in the extent to which they were driven by information-related goals at the outset of the interaction.

Network-mediated opportunity-based information seeking arose through two primary social processes. First, from 
human-related or document-related information seeking interactions which were made possible by prior interactions that constituted one person as available and approachable to the other, thus reducing the social risk associated with information seeking. In this way, interactions in information networks over time set a relational stage for information seeking, such that participants felt that they could seek information from these trusted others without hesitation. Second, interactions in information networks helped to create situations in which seeking information about HIV/AIDS seemed "natural" or relevant to the present interaction, thus removing some of the potential social awkwardness involved with talking about the issue. Thus, usually in response to the issue being raised by another person, participants comfortably asked questions, clarified concerns, and requested documents about the disease. Such information seeking thus tended to take place as a part of a flow of conversation and interaction. As I will describe below, such opportune situations arose in close, trusting relationships as well as more casual relationships.

Network-mediated information opportunity with family members and friends. On a relational level, interpersonally constituted "availability" and "approachability" appeared to be powerful facilitators of information seeking related to HIV/AIDS via social networks. Key supporters of PHAs and their friends/family members meticulously showed their availability and interest in helping them by offering to help whenever and however it was needed, often repeatedly. Indeed, many PHAs said that people close to them continually assured them that they would be there for "anything you need," or as this close friend of a PHA said, "I just told her right from there, that I'm there for you, anything you want."

If and when they were approached for help, both informal and formal supporters also made it easier for the person seeking aid by presenting themselves as "approachable," particularly through their responsiveness, as this family member found of her close friends,

“...my brother was here just before he died, and he was really, really sick ... ended up in the hospital ... but I was able to phone up some friends and just say 'hey, this is going on, we need some help....'

With successful experiences of receiving information and other forms of help from their supporters, a relational context grew in which there was a feeling of trust that certain people were truly there for them and that they could be approached with minimal personal risk. The significance of this availability and approachability was evident when PHAs and their family members/friends emphasized the characteristics that they valued in their network members, such as this PHA who said of a close friend, "He would be there when I need him, if I was sick. If I need him, he's there."

In the context of ties through which PHAs and their family members/friends believed that information was available, and from people they felt comfortable approaching, it appeared that participants solicited information without hesitation. Indeed, when asked about how they would handle various needs for information and other forms of help, PHAs and friends/family members frequently said that they would "just call" or "go immediately to" people who had already made themselves available. Similarly, PHAs and their friends/family members felt that it was very straightforward to ask for documents or Web-based information from an available and approachable loved one, as this family member said, "...well she has a lot of literature on HIV so if there were any questions I could look it up...."

On a situational level, network-mediated information opportunities occurred when the topic of HIV/AIDS arose in a given interaction, thus creating socially comfortable circumstances for asking questions or seeking documents. For example, PHAs and their friends/family members indicated that HIV status disclosure, in addition to being a time of information exposure, was often a time of significant information opportunity. Such opportunity set the stage for dialogue and back-and-forth exchange of: verbalized understandings about the disease, personal experiences and concerns, interpersonal reassurances, and adjustments of previously held ideas. These parts of disclosure interactions thus included an interactive, nuanced, and personalized discussion of HIV/AIDS and its implications. For instance, this PHA said that when she disclosed her HIV status to others, she often responded to a number of questions about how the disease affects her life,

“... when you first tell someone that you're positive, there's so many questions, a lot of them are around lifespan, medication,

'what do you have to do?', 'do you have to go to the doctor all the time?', ... so a lot of information's given at that point for me."

Similarly, as a recipient of the news of a relative's HIVpositive status, this family member said that she asked her a number of questions about how to prevent transmission of the disease, a dialogue that led to her feeling comfortable spending time with her in all of the usual ways,

"I asked, 'I want to be here, so what precautions do I have to take? Because I don't want to take something to my kids, I don't want to get sick, but I don't want to not be around you, so what do I have to do?' Number One ... [s]o we talked all those out...."

Ongoing life with PHAs also provided people close to PHAs with many opportunities for asking questions and thus gaining information about the disease and PHAs' experiences of living with it. Again, these opportunities tended to flow out of daily interactions, rather than being somehow removed from them, as this family member of a PHA described, "If I see her taking her pills ... I'll ask her something if I'm thinking about it at the time ... like I don't call her up and ask her something ...." Similarly, PHAs and family members described many incidents when PHAs made statements about their experiences or plans, providing those with whom they were speaking an opportunity to ask a question, sometimes out of curiosity. As this PHA described, “...I keep talking about wanting to get a tattoo, and they're like 'well 
how can you do that? Are you allowed to do that?'." Similarly, a PHA who mentioned his or her medical appointments to others, even in passing, might stimulate inquiries from network members.

Nonverbal communication also set the stage for information seeking, such as when a PHA appeared tired or unwell. For example, this PHA described a discussion with a family member,

“...she said 'are you alright?' and I said 'yeh,' and she said, 'you just seem ... so tired, you look like you haven't slept. Are you not sleeping?' 'Yeh, I'm sleeping,' and she said 'is this the disease?' and I said 'yeh,' and she said 'is that always going to be like that?' and I said 'I don't know. ...' I tried to explain [it] to her...."

Additionally, conversations between PHAs and their loved ones occasionally turned to documents that the PHA was reading about the disease. At these times, some friends and family members requested copies of documents that the PHA in their lives recommended, as this PHA said,

"My mom asked me for all the books I was getting from [ASO name] and I gave them all to her and I, I just. The more information that goes out the better."

Unsurprisingly, interactions between PHAs were rich in situational opportunities for asking and answering questions, regardless of how close their relationships were. Some PHAs observed that when they had social conversations with other PHAs, the conversation often turned to asking each other questions about their health and treatment, "...what kind of meds are you on? What's your count? How are you doing?" Similarly, in conversations between PHAs, discussions about new HIV/AIDS-related publications arose intermittently. In those interactions, PHAs also loaned and borrowed HIV/AIDS documents from one another, as this PHA described,

"I know I've had some ... of those magazines that I give to PHAs because they don't receive them by mail or whatever, so I don't mind passing that information along. ..."

When PHAs were very open about their HIV status in their communities, the issue of HIV/AIDS was also raised from time to time in their broader social circles, which resulted in the asking and answering of questions. Some volunteeractivist PHAs also deliberately tried to "raise the issue" by encouraging their casual friends or acquaintances to talk to them about HIV/AIDS. Occasionally they did this by adorning themselves with visible symbols of the disease, as this PHA said,

"I had my AIDS pin on my coat. I wear it, no matter what coat I have on, I have that pin on, and that is a great conversation starter too, some people actually don't know what it's for. And they will ask, and you know, you can have a conversation about that that way."

Such activists were determined to disseminate HIV/AIDS information to others. They did this by implicitly raising the issue with those around them or speaking about their experiences with people they did not know well. Hence, they deliberately created situations in which other people could comfortably ask them about the disease.

\section{Network-mediated information opportunity with health} care/ service providers. On a relational level, health care and service providers helped to create information opportunity when they established their approachability and assured their clients/patients of their availability, behaviors that made clients/patients feel comfortable with the idea of asking them for information in the present or future. Establishing availability was quite often a deliberate part of developing a professional-client/patient alliance, as this health care provider described, "I'll try to reaffirm for them, 'you can call anytime with your questions'." As a result of provider approachability and availability, PHAs and friends/family member participants described having developed confidence that they would receive what they needed from their providers and did not hesitate to ask them for information. Such confidence was often reinforced based on past successful experiences of seeking information from them, as this PHA said of his health care team,

\footnotetext{
"I always emailed them, emailed them back and forth, and they were always there to respond to my emails, if they didn't know the answer to my question they'd always find it out for me. If I did have concerns. So I just pick up the phone or I send an email and they're always there."
}

The importance of availability and approachability among health care and service providers was emphasized by PHAs who felt strong connections with their formal caregivers, such as counsellors who were described as responsive in times of need, or a family physician who a PHA said, "would come in the middle of the night to your house ... he's that kind of support person." The significance of this availability was all the more evident in the accounts of people who felt that their formal caregivers were not there for them when needed, such as this PHA who was frustrated by his experience with an ASO representative at a time of crisis,

"I said 'well, when things don't happen, and you promised things and I moved here for your help, and you're not helping me ... you say you'll do one thing and then you don't. ..."

Similarly, this PHA was upset when she did not receive a response from her health care provider when she contacted her for information,"...[when] she's not there to respond.... [w] get a little bit upset and maybe a little bit disappointed...."

\section{Network-Mediated Legitimation}

Respondents recognized that HIV/AIDS expertise was not evenly distributed in their communities. Some people simply knew more about the disease than others. As a result, as suggested by Haythornthwaite's (1996) model, 


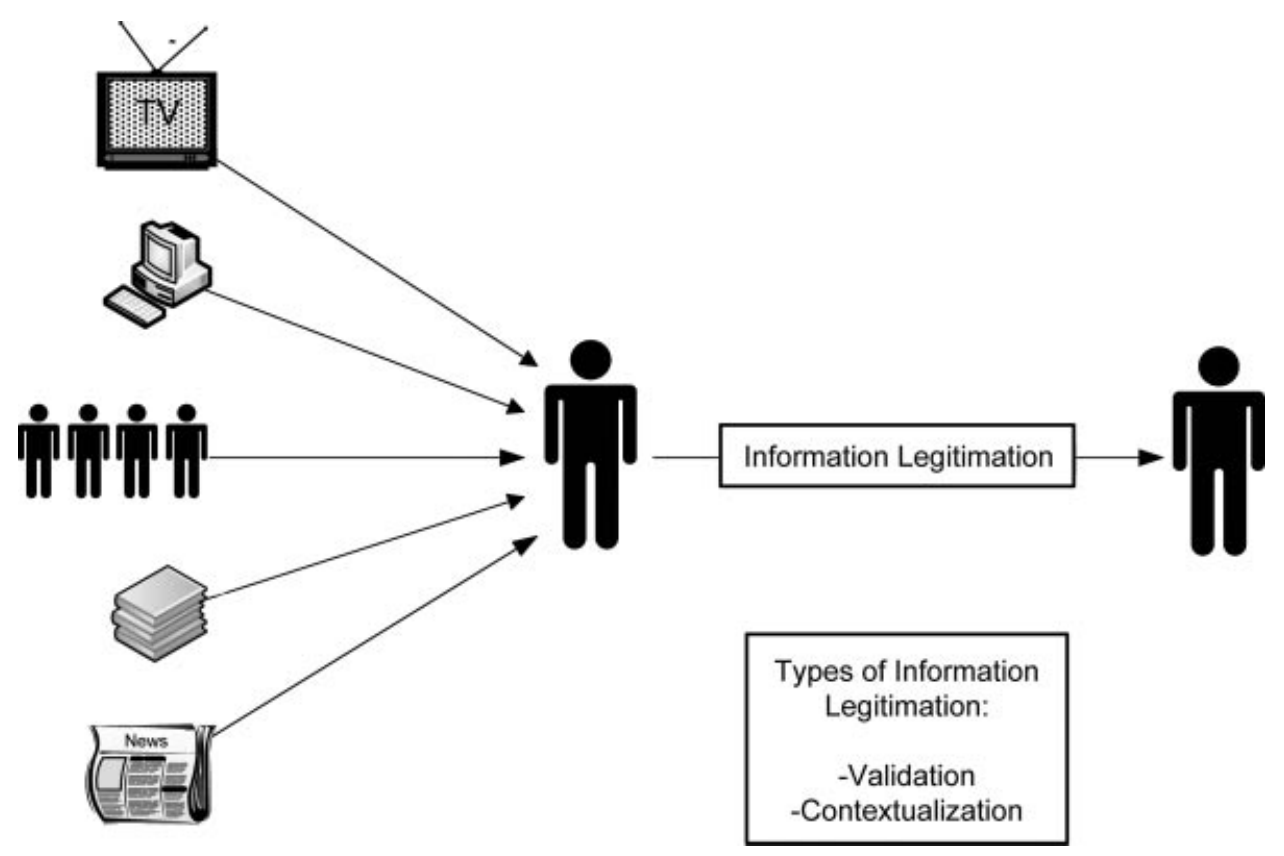

FIG. 5. Network-mediated legitimation. One network member asked another member for help with validating the quality of, or contextualizing, information obtained from elsewhere (e.g., the media, Internet, documents, or other people).

HIV-knowledgeable people became "go-to" people for "legitimating," or validating, information found elsewhere. Importantly for rural dwellers affected by HIV/AIDS, information legitimation activities also appeared to include processes of contextualization, or identification of the situationally or personally relevant. Moreover, PHAs often legitimated HIV/AIDS information by soliciting the experiences of their PHA peers. As Figure 5 shows, processes of legitimation involved one person obtaining information from a range of sources, such as the popular media, the Internet, print documents, and other people. Following this, as shown in Figure 5, the participant asked another person for help with information validation or contextualization. These processes appeared to be particularly important for participants as they navigated information that they received in the popular media; and for some, as they considered using the myriad of interventions intended to help them.

Network-mediated legitimation with family members and friends. For friends/family members, their ties with PHAs were generally the most important routes for legitimating HIV/AIDS information. As they watched television news, read newspapers, or surfed the Internet, friends/family members regularly encountered HIV/AIDS-related stories that they questioned, such as treatment breakthroughs or tales of people "cured" of HIV. When this happened, they consulted the PHA in their lives, whom they trusted to know the answer or verify the story, as this PHA described,

“... they'll want to confirm ... something that's hit the news $\ldots$ or the Internet ... there was a case of a man in England ... that said he was cured by taking vitamins. ... [a]nd they're like, 'is that true?'."
Similarly, some friends/family members also said that they would look for information independently first if they had a question, but they would always share it with the PHA they knew before accepting it. In a few cases, PHAs also turned to their HIV-negative family members/friends for legitimation of health or treatment information, with a few having decided to take complementary therapies at the encouragement of family members.

PHAs with ties to other PHAs often verified information that they received from the Internet or health care providers with each other. Many PHAs were very interested in finding out about other PHAs' side effects of antiretroviral drugs as a form of experiential legitimation of the "official" information from health care providers and pharmaceutical companies. Occasionally, they also made decisions about their own treatment as a result_-indeed, some health care providers noted that their PHA patients decided that they would never take certain drugs because of side effects they had heard about from their peers, and another provider noted that her patients sometimes asked to change their drug regimens to be on the same combinations as other people they knew. In a couple of cases, PHAs questioned the judgment of their health care providers if they recommended therapies that were unfamiliar to their PHA peers, as this alternative health care provider described,

“... a client came to me and he's suffering from jaundice, and I suggested that he take this herb that ... would help tonify the kidneys, and that's Fever Few.... [h]e went out right away and got some ... [then] he said, 'now, someone said I need Milk Thistle,' and I said, 'well, I don;t know why they would say that to you but I wouldn't advise that to you,' and he said, 'really? No one's ever heard of Fever Few before....' He called me a 'quack'...." 
Accordingly, relationships between PHAs were sufficiently important sources of information legitimation that PHAs occasionally rejected recommendations of individuals with institutionalized "authority," their care and service providers, when they did not match their peers' experiences.

Network-mediated legitimation with health care/service providers. Although family members of other PHAs could cause them to question the information provided by their health care and service providers, many PHAs saw these relationships as important anchors, especially when encountering new or unfamiliar information. As this PHA said, she turns to her health care and service providers when she comes across new information,

“. . . if it's something new, I never, never hesitate to run it past somebody who would be able to confirm. ..I always want to confirm it with somebody I consider to be trustworthy and reliable."

Relatedly, some PHAs also sought help from their health care providers to contextualize information that they encountered, thus helping them to know what was personally relevant, as this PHA did when she brought information she found on the Internet to her doctor, "[The Internet] gives me resources to go back to him and say "what does this mean? How does that affect me?"'

However, where the HIV-related knowledge of local family physicians was at issue, PHAs, their other care providers, and sometimes their families and friends, felt a need to try to compensate, through such strategies as legitimating HIV/AIDS information with more trusted sources. For example, a number of PHAs acted as informal liaisons with their HIV specialist care providers to try to convey needed information to their family physician, as this PHA described,

“. . .he's not versed in HIV.... He'll say to me, 'well you know what you need, what do you need?' Do I need drugs? Well I can pretty easily get the drugs. I don't like that part. But I will email the HIV clinic team, whether it's, if it's the pharmacist or the nurse or the doctor."

Another PHA checks with her HIV specialist nurse whenever her family physician prescribes general medications because she doesn't "trust his knowledge." Fortunately for rural dwellers affected by HIV/AIDS, information legitimation was often encouraged by formal caregivers, some of whom saw those exchanges as important "teaching moments," both about the disease itself and about critically evaluating information.

\section{Discussion}

\section{The Interactive Character of HIV/AIDS Information} Acquisition

Many study participants believed that it was necessary to be in direct social contact with people with HIV/AIDS knowledge and/or experience in order to gain HIV/AIDS information in their home communities. Thus, for ties in which an HIV-knowledgeable and/or -experienced person was present, drawing from Haythornthwaite's (1996) categories and Talja and Hansen's (2006) collaborative information behavior model, I identified several network-mediated processes that facilitated access to HIV/AIDS information in everyday life. By situating these network-mediated processes in the context of network ties, the present research contributes to a growing scholarly interest in the role of human agency and activity in networks (Emirbayer \& Goodwin, 1994; Felmlee, 2003). Moreover, this research helps to address a limitation of the structuralist approach that dominates social network research (Emirbayer \& Goodwin, 1994; Turner, 1998) and its information behavior applications, namely, its tendency to ignore agency and events that help to produce social structures (Day, 2005). Hence, I extend research by examining the interactions that contribute to the patterning of information network structures.

Returning to the specific processes identified, collaborative information seeking among network members involved interactions where participants shared an information need, and sought new HIV/AIDS information, either in a joint or tag team fashion. Participants' accounts of joint informationseeking activities incorporated behaviors that have also been observed in work settings, such as joint searching (Twidale et al., 1997) and using the Internet as a basis for problemsolving conversations (Crabtree et al., 1997; Reddy \& Jansen, 2008; Sonnenwald \& Pierce, 2000). Additionally, what I have called tag team searching is somewhat similar to the delegated or coordinated searching approaches observed in some workplaces (O'Day \& Jeffries, 1993; Poltrock et al., 2003; Prekop, 2002; Twidale et al., 1997). However, both of these forms of everyday life collaborative information seeking were less rigorously coordinated and undertaken in a more voluntary fashion than has been previously described in workplace settings. Additionally, in the context of dealing with HIV/AIDS in everyday life, collaborative information seeking also appeared to have more explicitly affective components, with these behaviors being perceived as either emotionally supportive or unwelcome and imposing, depending on the specific dynamics between network members. On a conceptual level, the loosely coordinated, voluntary, and affective nature of everyday life collaborative information seeking was sufficiently different from previously observed workplace behaviors to warrant the introduction of distinct terminology. These novel concepts also begin to elaborate the ways in which such dynamics may depart from those which have been observed in workplaces, suggesting important avenues for future research.

Network-mediated exposure consisted of participant interactions where HIV/AIDS information was laid open to view or brought forward to one network member by another. At these times, participants absorbed HIV/AIDS-related humanor document-related information by virtue of interacting with another person but without intending to gain HIV/AIDS information; as well, the other person in the exchange gave them information with or without a goal of "informing." 
This concept of network-mediated exposure thus has a different analytical focus from Haythornthwaite's (1996) network exposure concept, which formed the foundation for my initial analyses. In contrast to my interactive focus, her ideas focus on the ways in which individual network characteristics increase the probability of a person's exposure to information (p. 339). Hence, my concept of network-mediated exposure has more in common with three general phenomena described in the information behavior literature: (1) individuals gaining help or information through daily life activities without expressing a need or seeking it (McKenzie, 2003; Ross, 1999; Williamson, 2005; Wilson, 1997); (2) passive monitoring of everyday life events (Bates, 2002; McKenzie, 2003; Savolainen, 1995; Williamson, 2005); and (3) being given advice at the initiative of another person (McKenzie, 2003). Again, however, this concept differs from these ideas in its interactional, network-situated focus; in fact, one of the most conspicuous aspects of network-mediated HIV/AIDS information exchange in rural communities was that information was both given and received in a flow of interaction. Network-mediated exposure can thus be thought of as a specific type of network-mediated information acquisition and sharing, incorporating both "active and explicit and less goal-oriented exchanges" of "already acquired" information (Talja \& Hansen, 2006, p. 114). Following McKenzie's (2003) recommendation, the concept of network-mediated information exposure broadens the focus of research regarding incidental information acquisition by focusing equally on both an information giver and receiver. Such a focus holds promise for deeper explanation of the emergence and dynamics of nonpurposeful information acquisition.

Everyday life with people affected by HIV/AIDS also provided network-mediated, situationally bound opportunities for interpersonal information seeking, but these opportunities were generally taken up carefully because of the sensitive nature of the disease as a topic of conversation. In these cases, interpersonal information seeking took place when asking an HIV/AIDS-related question or requesting an HIV/AIDS-related document seemed "natural" or "relevant" to the present discussion-thus participants perceived that the time, conditions, or circumstances were "right" for asking about this sensitive topic. In such situations, information seeking took place as a part of a flow of network-based interaction. Similarly, Fisher (2005), as a part of "information grounds" theory, observes that information sharing can take place in spontaneous or serendipitous ways, as a part of a flow of conversation between people in social settings, or specific places. In contrast, though, my focus was not on the characteristics of places that facilitated this exchange of information; rather, I interrogated the relational and situational context of networks. Following Talja and Hansen's (2006) collaborative information behavior model, question-asking in moments of network-mediated opportunity was active and explicit, but did not originate with the directed goal of an information seeker, and the person who "raised the issue" did so in both explicit and implicit ways, such as by mentioning their experiences or by appearing physically unwell. By focusing on social situations as a facilitator of information acquisition and sharing, my research suggests that it is important to view interpersonal information acquisition as a negotiated process. Thus, the problem of network-level access to information might be fruitfully investigated by examining the patterns by which people create (or do not create) situations that make interpersonal information acquisition possible.

In addition, network-mediated opportunity included situations in which individuals directly asked their network members for information. As in the long-standing information behavior research focus on "active" information seeking (see, for example, Ellis, 2005; Krikelas, 1983; Kuhlthau, 2004; Wilson, 1999), information solicitation interactions tended to be initiated by a person with a conscious need or question in mind. However, my research broadened the temporal focus to show that the act of interpersonal information seeking was often founded on a history of relational work that defined one network member as "available" and "approachable" to another. Accordingly, taking a broad view of the timing of network-mediated information seeking may be appropriate, extending to the histories of information network ties, rather than solely focusing on the information seeking moment.

The aforementioned concepts of network-mediated information behavior help to describe some of the dynamics that can be present in everyday life collaborative information behavior, a phenomenon about which little has been known to date (Talja \& Hansen, 2006). These concepts also point to the highly interactive, network-distributed ways that people gain HIV/AIDS information, thus responding to calls for greater development of social approaches to information behavior research (Hjørland, 2002; Tuominen, Talja, \& Savolainen, 2002; Vakkari, 1997). Additionally, in showing the variety of social dynamics in which people share information, this research also raises broad questions about information practice. What role(s) might information services or systems play in these everyday collaborative information seeking and sharing contexts? Are there ways to support network-mediated information exposure? How can more network-mediated opportunities, or situations where information seeking seems "natural," be created within communities? If a relational history is the basis for comfort in interpersonal information seeking, should information professionals view their work as beginning with building relationships, before the information seeking moment and after that transaction ends? Would information services and systems profit from viewing the setting of their work as the social networks in which they are embedded, rather than simply at an institution or Web space? These reflections are in line with researchers in the field of collaborative information behavior who argue that, given the collaborative nature of much human information behavior, it is a practical weakness that information system design has historically targeted individual users without sufficient attention to their webs of relationships and collaborative activities (Foster, 2006; Hansen \& Järvelin, 2005; Poltrock et al., 2003; Reddy \& Jansen, 2008; Sonnenwald \& Pierce, 
2000; Twidale et al., 1997). What might be different about information services and systems if they are designed with network-mediated, collaborative, and interactive processes in mind? I would suggest that answering these questions may help us to envision ways in which services and systems can be more relevant to, and more extensively used by, those for whom they are intended.

\section{Information Exchange and Emotional Support Are Intertwined}

Perhaps due to its socially interactive character, the results of this research fit well with the observation from social support research that different forms of network-mediated aid can occur in overlapping and complex ways, particularly emotional support and information sharing (Berkman \& Glass, 2000, p. 848; Cutrona \& Russell, 1987; Wills, 1985). For example, many participants described interactions in which PHAs sought emotional support from their close friends/family, and while doing so, informed their loved ones about living with HIV/AIDS. Personal sharing between PHAs was also often experienced as emotionally supportive at the same time as it was informative, such as for PHAs who gained hope by talking to other PHAs. Moreover, as Salander (2002) noted, sharing health information can help to build relationships between ill people and their caregivers, a result which was evident in many participants' experiences of joint and tag team information seeking.

Study participants' emotionally rich experiences of network-mediated information exchange thus provide additional support for Harris \& Dewdney's (1994), Kuhlthau's (2004), and Nahl's (2007) assertions that information seeking has important affective dimensions. Results of the present study suggest that further investigation of the emotional dynamics of interpersonal information seeking and sharing is an important direction for future research; indeed, such investigations may help to explain the long-observed importance of other people as information sources (see, for example, Harris \& Dewdney, 1994). In terms of information practice, research regarding the affective aspects of information seeking may provide a rationale for thinking about health information professionals as potential sources of emotional comfort as well as information. If provision of emotional support is taken seriously as an aspect of health information practice, there may be a need to proactively attend to psychosocial aspects of information professional-client interactions. For example, future research might fruitfully examine whether the effectiveness of the information professional's "reference interview" (Ross, Nilsen, \& Dewdney, 2002) with clients might be improved through the deliberate application of basic counseling skills such as active listening, paraphrasing, and reflection of feelings (Nelson-Jones, 2007).

\section{Health Information Legitimation Is Network-Distributed}

Within the health care field, there has been much stated concern about the prevalence of poor quality of health information on the Internet (see, for example, Eysenbach, Powell, Kuss, \& Sa, 2002; Jadad \& Gagliardi, 1998) as well as consumers' inconsistent information quality assessment practices (see, for example, Eysenbach \& Kohler, 2002; Fox, 2006). As a result of these concerns, it has been argued that there is a need for: greater control of Internet information quality (see, for example, Childs, 2006; Risk \& Dzenowagis, 2001); improved understanding of Website quality indicators (see, for example, Greenberg, D'Andrea, \& Lorence, 2004; Mayer, Darmoni, Fiene, Kohler, Roth-Berghofer, \& Eysenbach, 2003); and improved health information quality assessment skills among health care consumers (see, for example, Charnock, 1998; Wilson, 2002).

While these strategies may indeed be valuable in some circumstances, this research also suggests that network ties with HIV/AIDS-knowledgeable people can provide an important pathway for information legitimation; in fact, this appeared to be a key strategy pursued by many rural dwellers. Additionally, some PHAs believed that learning about the experiences of other PHAs helped them to evaluate HIV/AIDS-related information, and others valued assistance in understanding how HIV/AIDS information was personally relevant. The information legitimation activities of participants, however, differed from Haythornthwaite's (1996) concept of information legitimation, which she linked primarily to tie strength between network members, suggesting that information legitimation is more likely to occur within strong ties (p. 339). In the present study, uneven distribution of HIV/AIDS knowledge meant that perceived expertise of network members was a crucial aspect of information legitimation, rather than merely tie strength.

If the perceived legitimacy of health information is often constituted in interaction between people, as this research suggests, it follows that interventions that address the social character of information legitimation may be appropriate. For instance, perhaps an alternative strategy for dealing with concerns about health information quality on the Internet could be to develop programs that cultivate network ties that are sufficiently knowledgeable to legitimate information. Alternatively, there may be a need to understand the ways in which increased "community capacity" (Chaskin, 2001), developed through specific efforts to enhance local knowledge, might be needed to facilitate HIV/AIDS information legitimation. Furthermore, network-based tactics for improving access to HIV/AIDS information in rural communities might include the creation of opportunities for PHAs to interact and expansion of providers' efforts to communicate HIV/AIDS information in ways that make it personally "meaningful." Such network-based information legitimation strategies may be more realistic than current approaches, since it is inherently difficult to control something as rapidly changing as health information content on the Internet or to reach every individual in need of information literacy skills development. Further research is needed to better understand the potentially interactive, network-driven basis of health information legitimation, and to grasp the ways in which this dynamic might be practically leveraged. 


\section{Conclusion}

Through this research I sought to understand how ruraldwelling PHAs and their friends/family members acquire and share HIV/AIDS information in social networks. Results of this study suggest that HIV/AIDS information behavior among rural dwellers is undertaken through five networkmediated information exchange processes that I have introduced in this paper: joint seeking, tag team seeking, exposure, opportunities, and legitimation. These novel concepts point to the dynamic nature of information network ties, thus extending prior research that has focused more on documenting the existence and structure of such networks. Additional research is needed to further develop the concepts introduced in this research, to map their interrelationships, and to determine their wider applicability across contexts.

Furthermore, this research offers an early step in illuminating everyday life collaborative information behavior, highlighting the fact that everyday life behavior was more voluntary and loosely coordinated than has been described in workplace settings. Additionally, such behavior was often seen to be laden with emotional significance in ways that have not been described in workplace-based research. Such findings suggest a need to further examine the similarities and differences between collaborative information behavior in different contexts. Moreover, it would be valuable to further investigate the affective dimensions of collaborative information behavior, particularly in an illness context.

Finally, a key finding of this research was that information behaviors that are often analyzed as individual actions, such as information seeking, nonpurposeful information acquisition, and credibility assessment, can all be located within interactive networks of social relationships. Consequently, the insights emanating from this study suggest that health information practice might benefit from a focus on program strategies such as building information network capacity, developing collaborative information retrieval systems, peer networking, emotional support, and relationship-building in addition to the more traditional library-related concerns of reference encounters, collections, and institutional Web sites.

\section{Acknowledgments}

I thank the people who participated in this study, as well as community partners in each region. Additionally, I thank my dissertation advisor, Dr. Roma Harris, for feedback on early versions of this content, as well as two anonymous JASIST reviewers for useful editorial advice. Financial support for this project was generously provided by the Canadian Institutes for Health Research under the Federal Initiative to address HIV/AIDS in Canada and the Social Sciences and Humanities Research Council's Doctoral Fellowship program.

\section{References}

Abrahamson, J.A., Fisher, K.E., Turner, A.G., Durrance, J.C., \& Turner, T.C. (2008). Lay information mediary behavior uncovered: Exploring how nonprofessionals seek health information for themselves and others online. Journal of the Medical Libraries Association, 96(4), 310-323.

Adelman, M.B., \& Frey, L.R. (1997). The fragile community: Living together with AIDS. Mahwah, NJ: Lawrence Erlbaum.

Agada, J. (1999). Inner-city gatekeepers: An exploratory survey of their information use environment. Journal of the American Society for Information Science, 50(1), 74-85.

Allen, T.J. (1977). Managing the flow of technology: Technology transfer and the dissemination of technological information within the R\&D organization. Cambridge, MA: MIT Press.

Bates, M.J. (2002). Toward an integrated model of information seeking and searching. New Review of Information Behavior Research, 2, $1-15$.

Berkman, L., \& Glass, T. (2000). Social integration, social networks, social support and health. In L. Berkman \& I. Kawachi (Eds.), Social epidemiology (p. 51). New York: Oxford University Press.

Bian, Y.J. (1997). Bringing strong ties back in: Indirect ties, network bridges, and job searches in China. American Sociological Review, 62(3), 366-385.

Brashers, D.E. (2001). HIV and uncertainty: Managing treatment decision making. Focus: A Guide to AIDS Research, 16(9), 5-6.

Brashers, D.E., Haas, S.M., Neidig, J.L., \& Rintamaki, L.S. (2002). Social activism, self-advocacy, and coping with HIV illness. Journal of Social and Personal Relationships, 19(1), 113-134.

Brashers, D.E., Neidig, J.L., Haas, S.M., Dobbs, L.K., Cardillo, L.W., \& Russell, J.A. (2000). Communication in the management of uncertainty: The case of persons living with HIV or AIDS. Communication Monographs, 67(1), 63-84.

Brashers, D.E., Neidig, J.L., Russell, J.A., Cardillo, L.W., Haas, S.M., Dobbs, L.K., et al. (2003). The medical, personal, and social causes of uncertainty in HIV illness. Issues in Mental Health Nursing, 24(5), 497-522.

Brashers, D.E., Neidig, J.L., \& Goldsmith, D.J. (2004). Social support and the management of uncertainty for people living with HIV. Health Communication, 16(3), 305-331.

Brenner, M. (1985). Intensive interviewing. In M. Brenner, J. Brown, \& D. Canter (Eds.), The research interview: Uses and approaches (pp. 147-162). London: Academic Press.

Bruce, H., Cleal, B., Fidel, R., \& Pejtersen, A.M. (2004). A multidimensional approach to the study of human-information interaction: A case study of collaborative information retrieval. Journal of the American Society for Information Science and Technology, 55(11), 939-953.

Bruce, H., Fidel, R., Pejtersen A.M., Dumais, S., Grudin, J., \& Poltrock, S. (2003). A comparison of the collaborative information retrieval behavior of two design teams. New Review of Information Behavior Research, 4, 139-153.

Charnock, D. (1998). The DISCERN handbook: Quality criteria for consumer health information on treatment choices. Retrieved June 13, 2009 , from http://www.discern.org.uk/discern.pdf

Charon, J.M. (1998). Symbolic interactionism: An introduction, an interpretation, an integration (6th ed.). Upper Saddle River, NJ: Prentice-Hall.

Chaskin, R.J. (2001). Building community capacity. New York: A. de Gruyter.

Chen, X., \& Siu, L.L. (2001). Impact of the media and the internet on oncology: Survey of cancer patients and oncologists in Canada. Journal of Clinical Oncology, 19(23), 4291-4297.

Childs, S. (2006). Judging the quality of internet-based health information. Performance Measurement and Metrics, 6(2), 80-96.

Crabtree, A., Twidale, M.B., O'Brien, J., \& Nichols, D.M. (1997). Talking in the library: Implications for the design of digital libraries. In Proceedings of the Second ACM Conference on the Theory and Practice of Digital Libraries (pp. 221-228). New York: ACM Press.

Crane, D. (1972). Invisible colleges. Chicago: University of Chicago Press. Crawford, S. (1971). Informal communication among scientists in sleep research. Journal of the American Society for Information Science, 22(5), 301-310.

Creswell, J.W. (2003). Research design: Qualitative, quantitative and mixed methods approaches (2nd ed.). Thousand Oaks, CA: Sage. 
Cronin, B. (1982). Invisible colleges and information transfer: A review and commentary with particular reference to the social sciences. Journal of Documentation, 38(3), 212-236.

Cutrona, C.E., \& Russell, D.W. (1987). The provisions of social relationships and adaptations to stress. Advances in Personal Relationships, 1(1), 37-67.

Davenport, E., \& Hall, H. (2002). Organizational knowledge and communities of practice. Annual Review of Information Science and Technology, $36,172-227$

Day, R. (2005). Poststructuralism and information studies. Annual Review of Information Science and Technology, 39, 575-609.

Degenne, A., \& Forsé, M. (1999). Introducing social networks (A. Borges, Trans.). London: Sage.

Dervin, B. (1983). Information as a user construct: The relevance of perceived information needs to synthesis and interpretation. In S.A. Ward \& L.J. Reed (Eds.), Knowledge structure and use: Implications for synthesis and interpretation (pp. 155-183). Philadelphia: Temple University Press.

Dervin, B. (1992). From the mind's eye of the user: The sense-making qualitative-quantitative methodology. In J.D. Glazier \& R.R. Powell (Eds.), Qualitative research in information management (pp. 61-84). Englewood, CA: Libraries Unlimited.

Dervin, B., \& Fraser, B. (1985). How libraries help. Sacramento, CA: California State Library.

Ellis, D. (2005). Ellis's model of information-seeking behavior. In K.E. Fisher, S. Erdelez, \& E.F. McKechnie (Eds.), Theories of information behavior: A researcher's guide (pp. 138-142). Medford, NJ: Information Today.

Emirbayer, M., \& Goodwin, J. (1994). Network analysis, culture and the problem of agency. American Journal of Sociology, 99(6), 1411-1154.

Erdelez, S., \& Rioux, K. (2000). Sharing information encountered for others on the web. New Review of Information Behavior Research, 1, 219-233.

Erickson, B.H. (1979). Some problems of inference from chain data. Sociological Methodology, 10, 276-302.

Eysenbach, G., \& Kohler, C. (2002). How do consumers search for and appraise health information on the world wide web? Qualitative study using focus groups, usability tests, and in-depth interviews. British Medical Journal, 324(7337), 573-577.

Eysenbach, G., Powell, J., Kuss, O., \& Sa, E.R. (2002). Empirical studies assessing the quality of health information for consumers on the world wide web: A systematic review. JAMA: Journal of the American Medical Association, 287(20), 2691-2700.

Felmlee, D.H. (2003). Interaction in social networks. In J. Delamater (Ed.), Handbook of social psychology (pp. 389-409). Davis, CA: Kluwer Academic/Plenum Publishers.

Feltwell, A.K., \& Rees, C.E. (2004). The information-seeking behaviors of partners of men with prostate cancer: a qualitative pilot study. Patient Education and Counseling, 54(2), 179-185.

Fidel, R., Petjersen, A.M., Cleal, B., \& Bruce, H. (2004). A Multidimensional approach to the study of human-information interaction: A case study of collaborative information retrieval. Journal of the American Society for Information Science, 55(11), 939-953.

Fisher, K.E. (2005). Information grounds. In K.E. Fisher, S. Erdelez, \& E.F. McKechnie (Eds.), Theories of information behavior: A researcher's guide (pp. 185-190). Medford, NJ: Information Today.

Fitch, M.I., \& Allard, M. (2007). Perspectives of husbands of women with breast cancer: Information needs. Canadian Oncology Nursing Journal, 17(2), 79-90.

Foster, J. (2006). Collaborative information seeking and retrieval. Annual Review of Information Science and Technology, 40, 329-356.

Fox, S. (2006). Online health search 2006: Most internet users start at a search engine when looking for health information online. Very few check the source and date of the information they find. Retrieved June 13, 2009, from http://www.pewinternet.org/ /media/Files/Reports/2006/PIP_Online_ Health_2006.pdf.pdf

Gilchrist, V.J., \& Williams, R.L. (1999). Sampling in qualitative inquiry. In B.F. Crabtree \& M.W.L. (Eds.), Doing qualitative research (2nd ed., pp. 71-88). Thousand Oaks, CA: Sage.
Glaser, B.G., \& Strauss, A.L. (1967). The discovery of grounded theory. New York: A. de Gruyter.

Granovetter, M.S. (1973). The strength of weak ties. American Journal of Sociology, 78(6), 1360-1380.

Greenberg, L., D’Andrea, G., \& Lorence, D. (2004). Setting the public agenda for online health search: A white paper and action agenda. Journal of Medical Internet Research, 6(2), e18.

Hansen, P., \& Järvelin, K. (2004). Collaborative information searching in an information intensive work domain: Preliminary results. Journal of Digital Information Management, 2(1), 26-30.

Hansen, P., \& Järvelin, K. (2005). Collaborative information retrieval in an information-intensive domain. Information Processing and Management, 41(5), 1101-1119.

Harris, R.M., \& Dewdney, P. (1994). Theory and research on informationseeking. In Barriers to information: How formal help systems fail battered women (pp. 7-34). Westport, CT: Greenwood Press.

Haythornthwaite, C. (1996). Social network analysis: An approach and technique for the study of information exchange. Library \& Information Science Research, 18(4), 323-342.

Haythornthwaite, C. (1998a). A social network study of the growth of community among distance learners. Information Research, 4(1), paper 49.

Haythornthwaite, C. (1998b). Work, friendship and media use for information exchange in a networked organization. Journal of the American Society for Information Science, 49(12), 1101-1114.

Haythornthwaite, C. (2000). Online personal networks: Size, composition and media use among distance learners. New Media and Society, 2(2), 195-226.

Health Canada. (2000). National HIV/AIDS treatment information environmental scan: Final report. Ottawa: Health Canada.

Hersberger, J.A. (2003). A qualitative approach to examining information transfer via social networks among homeless populations. New Review of Information Behavior Research, 4(1), 95-108.

Hertzum, M. (2008). Collaborative information seeking: The combined activity of information seeking and collaborative grounding. Information Processing and Management, 44(2), 957-962.

Hjørland, B. (2002). Epistemology and the Socio-Cognitive Perspective in Information Science. Journal of the American Society for Information Science, 53(4), 257-270.

Hogan, T.P., \& Palmer, C.L. (2005). Information preferences and practices among people living with HIV/AIDS: Results from a nationwide survey. Journal of the Medical Library Association, 93(4), 431-439.

Huber, J.T., \& Cruz, J.M. (2000). Information needs and information-seeking behaviors of HIV positive men and women. Medical Reference Services Quarterly, 19(3), 39-48.

Hyldegard, J. (2006). Collaborative information behavior-exploring Kuhlthau's Information Search Process model in a group-based educational setting. Information Processing \& Management, 42(1), 276-298.

Hyldegard, J. (2009). Beyond the search process-Exploring group members' information behavior in context. Information Processing \& Management, 45, 142-158.

Jadad, A.R., \& Gagliardi, A. (1998). Rating health information on the Internet: Navigating to knowledge or to Babel? JAMA: Journal of the American Medical Association, 279(8), 611-614.

Jeong, W. (2004). Unbreakable ethnic bonds: Information-seeking behavior of Korean graduate students in the United States. Library \& Information Science Research, 26(3), 384-400.

Krikelas, J. (1983). Information-seeking behavior: Patterns and concepts. Drexel Library Quarterly, 19(2), 5-20.

Kronick, D.A. (2001). The commerce of letters: Networks and "invisible colleges" in seventeenth- and eighteenth-century Europe. Library Quarterly, 71(1), 28-43.

Kuhlthau, C.C. (2004). Seeking meaning: A process approach to library and information services (2nd ed.). Westport, CT: Libraries Unlimited.

MacKenzie, M.L. (2005). Managers look to the social network to seek information. Information Research, 10(2), paper 216.

Mason, T.M. (2008). Wives of men with prostate cancer postbrachytherapy: Perceived information needs and degree of being met. Cancer Nursing, 31(1), 32-37. 
Mayer, M.A., Darmoni, S.J., Fiene, M., Kohler, C., Roth-Berghofer, T.R., \& Eysenbach, G. (2003). MedCIRCLE: Collaboration for Internet rating, certification, labelling and evaluation of health information on the WorldWide-Web. Studies in Health Technology and Informatics, 95, 667-672.

McKenzie, P.J. (2003). A model of information practices in accounts of everyday life information seeking. Journal of Documentation, 59(1), $19-40$.

Metoyer-Duran, C. (1993). The information and referral process in culturally diverse communities. Reference Quarterly, 32, 359-371.

Nahl, D. (2007). The centrality of the affective in information behavior. In D. Nahl \& D. Bilal (Eds.), Information and emotion: The emergent affective paradigm in information behavior research and theory (pp. 51-84). Medford, NJ: American Society for Information Science \& Technology.

Nelson-Jones, R. (2007). Basic counselling skills: A helper's manual (2nd ed.). Thousand Oaks, CA: Sage.

O'Day, V.L., \& Jeffries, R. (1993, November). Information artisans: Patterns of result sharing by information searchers. Paper presented at the Conference on Supporting Group Work, Milpitas, CA.

Oxford English Dictionary. (1989a). expose, v. In OED Online (2nd ed.). Oxford, UK: Oxford University Press.

Oxford English Dictionary. (1989b). opportunity, n. In OED Online (2nd ed.). Oxford, UK: Oxford University Press.

Patton, M.Q. (1990). Qualitative evaluation and research methods (2nd ed.). Newbury Park, CA: Sage.

Pettigrew, K.E. (1999). Waiting for chiropody: Contextual results from an ethnographic study of the information behavior among attendees at community clinics. Information Processing \& Management, 35(6), 801-817.

Pettigrew, K.E. (2000). Lay information provision in community settings: How community health nurses disseminate human services information to the elderly. Library Quarterly, 70(1), 47-85.

Poltrock, S., Grudin, J., Dumais, S., Fidel, R., Bruce, H., \& Pejtersen, A.M. (2003). Information seeking and sharing design teams. In K. Schmidt, \& M. Pendergast (Chairs), Proceedings of the 2003 International ACM SIGGROUP Conference on Supporting Group Work, (pp. 239-247). New York: ACM Press.

Prekop, P. (2002). A qualitative study of collaborative information seeking. Journal of Documentation, 58(5), 533-547.

Ratnam, S., Hogan, K., \& Hankins, C. (1996). Prevalence of HIV infection among pregnant women in Newfoundland. Canadian Medical Association Journal, 154(7), 1027-1032.

Raupach, J.C., \& Hiller, J.E. (2002). Information and support for women following the primary treatment of breast cancer. Health Expectations, 5(4), 289-301.

Raynor, D.K., Savage, I., Knapp, P., \& Henley, J. (2004). We are the experts: People with asthma talk about their medicine information needs. Patient Education \& Counseling, 53(2), 167-174.

Reddy, M.C., \& Jansen, B.J. (2008). A model for understanding collaborative information behavior in context: A study of two health care teams. Information Processing and Management, 44(1), 256-273.

Reddy, M.C., \& Spence, P.R. (2008). Collaborative information seeking: A field study of a multidisciplinary patient care team. Information Processing and Management, 44(1), 242-255.

Rees, C.E., \& Bath, P.A. (2000). The information needs and source preferences of women with breast cancer and their family members: A review of the literature published between 1988 and 1998. Journal of Advanced Nursing, 31(4), 833-841.

Rieh, S.Y. (2004). On the Web at home: Information seeking and Web searching in the home environment. Journal of the American Society for Information Science, 55(8), 743-753.

Rioux, K. (2005). Information acquiring-and-sharing. In K.E. Fisher, S. Erdelez, \& E.F. McKechnie (Eds.), Theories of information behavior: A researcher's guide (pp. 169-173). Medford, NJ: Information Today.

Risk, A., \& Dzenowagis, J. (2001). Review of Internet health information quality initiatives. Journal of Medical Internet Research, 3(4), e28.

Ross, C.S. (1999). Finding without seeking: The information encounter in the context of reading for pleasure. Information Processing \& Management, 35(6), 783-799.
Ross, C.S., Nilsen, K., \& Dewdney, P. (2002). Conducting the reference interview: A how-to-do-it manual for librarians. New York: NealSchuman.

Salander, P. (2002). Bad news from the patient's perspective: An analysis of the written narratives of newly diagnosed cancer patients. Social Science and Medicine, 55(5), 721-732.

Sandstrom, K.L. (1996). Searching for information, understanding and selfvalue: The utilization of peer support groups by gay men with HIV/AIDS Social Work in Health Care, 23(4), 31-74.

Savolainen, R. (1995). Everyday life information seeking: Approaching information seeking in the context of "way of life." Library \& Information Science Research, 17(3), 259-294.

Scott, J. (1991). Social network analysis: A handbook. London: Sage.

Sonnenwald, D.H., \& Lievrouw, L.A. (1997, August). Collaboration during the design process: A case study of communication, information behavior and project performance. Paper presented at the Information Behaviour Conference (ISIC), Tampere, Finland. Retrieved June 16, 2009, from http://informationr.net/isic/ISIC1996/96_sonnenwald.pdf

Sonnenwald, D.H., \& Pierce, L.G. (2000). Information behavior in dynamic group work contexts: Interwoven situational awareness, dense social networks and contested collaboration in command and control. Information Processing and Management, 36(3), 461-479.

Spirig, R. (1998). Support groups for people living with HIV/AIDS: A review of literature. Journal of the Association of Nurses in AIDS Care, 9(4), $43-55$.

Strauss, A., \& Corbin, J. (1998). Basics of qualitative research: Techniques and procedures for developing grounded theory. Thousand Oaks, CA: Sage.

Talja, S. (2002). Information sharing in academic communities: Types and levels of collaboration in information seeking and use. New Review of Information Behavior Research, 3, 143-159.

Talja, S., \& Hansen, P. (2006). Information sharing. In A. Spink \& C. Cole (Eds.), New directions in human information behavior (pp. 113-134). Dordrecht, Netherlands: Springer.

Taylor, D. (2002). Synthesizing information about HIV/AIDS and its treatment. In Making care visible: Antiretroviral therapy and the health work of people living with HIV/AIDS (pp. 105-121). Toronto, Canada: Making Care Visible Working Group.

Thompson, J.K. (1996). Crossing boundaries: Knowledge, disciplinarities, and interdisciplinarities. Charlottesville, VA: University Press of Virginia.

Tuominen, K., Talja, S., \& Savolainen, R. (2002). Discourse, cognition, and reality: Toward a social constructionist metatheory for library and information science1. In H. Bruce, R. Fidel, P. Ingwersen, \& P. Vakkari (Eds.), Emerging frameworks and methods: CoLIS 4. Proceedings of the Fourth International Conference on Conceptions of Library and Information Science (pp. 271-283). Seattle, WA: Libraries Unlimited.

Turner, J.H. (1998). French, British and American variations of structural theorizing. In The structure of sociological theory (pp. 478-490). London: Wadsworth.

Twidale, M.B., Nichols, D.M., \& Paice, C.D. (1997). Browsing is a collaborative process. Information Processing and Management, 33(6), 761-783.

Vakkari, P. (1997). Information seeking in context: A challenging metatheory. In P. Vakkari, R. Savolainen, \& B. Dervin (Eds.), Information seeking in context: Proceedings of an International Conference on Research in Information Needs, Seeking and Use in Different Contexts (pp. 451-464). London: Taylor Graham.

van der Poel, M.G.M. (1993). Delineating personal support networks. Social Networks, 15(1), 49-70.

Veinot, T.C., Harris, R.M., Bella, L., Rootman, I., \& Krajnak, J. (2006). HIV/AIDS information exchange in rural communities: Preliminary findings from a three province study. Canadian Journal of Information and Library Science, 30(3/4), 271-290.

Wasserman, S., \& Faust, K. (1994). Social network analysis: Methods and applications. Cambridge, UK: Cambridge University Press. 
Williamson, K. (2005). Ecological theory of human information behavior. In K.E. Fisher, S. Erdelez, \& E.F. McKechnie (Eds.), Theories of information behavior: A researcher's guide (pp. 128-132). Medford, NJ: Information Today.

Wills, T.A. (1985). Supportive functions of interpersonal relationships. In S. Cohen \& S.L. Syme (Eds.), Social support and health (pp. 61-82). Orlando, FL: Academic Press.

Wilson, P. (2002). How to find the good and avoid the bad or ugly: A short guide to tools for rating quality of health information on the internet. British Medical Journal, 324(7337), 598-602.
Wilson, T.D. (1997). Information behavior: An interdisciplinary perspective. Information Processing and Management, 33(4), 551-572.

Wilson, T.D. (1999). Models of information behavior research. Journal of Documentation, 55(3), 249-270.

Wilson, T.D. (2000). Human information behavior. Informing Science, 3(2), 49-55.

Yakubovich, V. (2005). Weak ties, information, and influence: How workers find jobs in a local Russian labor market. American Sociological Review, $70(3), 408-421$. 